\title{
DOSE-DEPENDENT RECOMBINATION IN SILICON IRRADIATED BY GAMMA RAYS AS DETERMINED BY MICROWAVE ABSORPTION TRANSIENTS
}

\author{
J. Vaitkus ${ }^{\mathrm{a}}$, Z. Li ${ }^{\mathrm{b}}$, J. Härkönen ${ }^{\mathrm{c}}$, and E. Gaubas ${ }^{\mathrm{a}}$ \\ ${ }^{a}$ Institute of Materials Science and Applied Research, Vilnius University, Saulètekio 10, LT-10223 Vilnius, Lithuania \\ E-mail: eugenijus.gaubas@ff.vu.lt \\ ${ }^{\mathrm{b}}$ Brookhaven National Laboratory, Upton, NY 11973-5000, USA \\ ${ }^{\mathrm{c}}$ Helsinki Institute of Physics, Helsinki University, Finland and CERN/PH, 1211 Geneva, Switzerland
}

Received 14 September 2006

\begin{abstract}
Variation of carrier lifetime in magnetic Czochralski and float zone silicon irradiated with Co-60 $\gamma$-rays was investigated for doses in the range from 50 to $400 \mathrm{MRad}$. The inverse carrier lifetime was found to increase approximately linearly with dose and the carrier capture cross-section has been determined. The recombination and trapping constituents within recombination transients have been distinguished by combining analyses of the excess carrier decays measured using microwave absorption by free carriers for different excitation conditions and temperatures. The activation energies of traps and recombination centres have been determined from the carrier lifetime dependence on temperature.
\end{abstract}

Keywords: carrier recombination and trapping, radiation defects, silicon

PACS: $72.20 . \mathrm{Jv}$

\section{Introduction}

Silicon detectors used in high energy physics need better radiation hardness for future Large Hadron Collider experiments. One way to improve silicon material radiation hardness is to fabricate the particle detectors on oxygen rich substrates such as high-resistivity magnetic Czochralski silicon (MCZ) or oxygenated float zone silicon (DOFZ) [1-3]. $\gamma$-rays induce point defects in silicon that interact with interstitial oxygen forming oxygen-radiation defect complexes. Furthermore, the $\gamma$-rays are known to activate oxygen associated thermal donors (TDs) that may be electrically inactive after the device fabrication process. Recently, there has been strong interest in the manipulation of the silicon's effective resistivity using thermal treatments to generate TDs [3-6]. The complicated interaction between the radiation defects, interstitial oxygen, TDs, and $\gamma$-rays alters the effective space charge concentration and thus affects the operation of particle detectors, especially in the case of space charge sign inversion $[5,6]$. This interaction results in changes of recombination and trapping processes in the material due to the reactions of radiation defects and their oxygen related complexes. Also, investigation of recombination pro- cesses can reveal peculiarities of defect system transformations. Nonequilibrium conductivity decay data are important for modelling of Si cryogenic detectors for high energy experiments [7].

In this work, the decay of photoconductivity and carrier lifetime variations were measured at different temperatures in $\gamma$-ray irradiated MCZ samples. The $n$ and $p$-type MCZ silicon samples were irradiated with Co-60 $\gamma$-ray doses ranging from 50 to $370 \mathrm{MRad}$. The lifetime measurements were based on the decay of photoconductivity after excitation by a short light pulse. The decay in the photoconductivity was measured by microwave absorption (MWA), which depends on the sample conductivity. The transient has recombination and trapping components, which can be distinguished by combining analyses of the transient dependence on light excitation intensity, bias illumination (BI), and temperature, allowing the changes of the deep level system to be studied.

To investigate the influence of interstitial oxygen and TDs on the recombination and trapping processes, the results from studies of $\mathrm{MCZ}$ were compared with those of standard float zone (FZ) silicon. A nearly linear increase of the inverse recombination lifetime with the irradiation dose confirms the existence of point defect 
formation processes in MCZ samples. A comparison of the effects of excess carrier density and temperature on recombination and trapping constituents of carrier decay transients revealed interaction between radiationand processing-induced defects. It has been observed that the trapping process contribution into the photoconductivity decay depends on the irradiation and the recombination and trapping roles are more dependent on irradiation in $n$-Si than in $p$-Si.

\section{Samples and experimental techniques}

The samples under investigation are listed in Table 1. Most of the samples were $20 \times 20 \mathrm{~mm}^{2}, 300 \mu \mathrm{m}$ thick, homogeneous $p$ - $(A)$ and $n$-type $(B) \mathrm{MCZ}$ Si wafers. 'Twin-samples', one a thermally treated wafer $(1,2)$ and the other a non-heated wafer $(3,4)$, were fabricated to investigate the effect of thermal donors. TD processing of one of the twin-samples was made by heating for $30 \mathrm{~min}$ in an inert $\mathrm{N}_{2}$ atmosphere at $450{ }^{\circ} \mathrm{C}$. The samples were irradiated with Co-60 $\gamma$-rays to a dose of 50 MRad. Carrier lifetime and Fourier transform infrared absorption spectroscopy (FTIR) investigations were performed on the irradiated samples. The irradiated, non-heated wafers were then cut into four $10 \times 10 \mathrm{~mm}^{2}$ pieces and irradiated with additional doses of $80,160,270$, and 320 MRad, respectively. Thus, the fourth sample of the set collected a total irradiation dose of 370 MRad.

A pad-detector, fabricated on standard $n$-type $\mathrm{FZ} \mathrm{Si}$, was irradiated with $400 \mathrm{MRad}$ of Co-60 $\gamma$-rays. A $2 \mathrm{~mm}$ diameter optical window in the centre of the detector and a $1 \mathrm{~mm}$ wide boundary of the detector area were left non-metallized, and utilized for MWA measurements.

Room temperature FTIR spectroscopy was employed to measure the concentration of the interstitial oxygen $\left(\mathrm{O}_{\mathrm{i}}\right)$. The measurements were carried out by a Perkin Elmer GX FTIR spectrometer equipped with a DGTS detector.

Excess carrier density relaxation was measured using microwave absorption [8], combining analyses of the dependence of excess carrier decay on excitation intensity, bias illumination, and temperature. Excess carriers were generated in the bulk of the samples using $1064 \mathrm{~nm}$ wavelength light from a YAG : $\mathrm{Nd}^{3+}$ laser with $10 \mathrm{~ns}$ pulse duration. The excess carrier density decays due to recombination influenced by carrier trapping. The excess conductivity decay was probed using the free carrier absorption of $10 \mathrm{GHz}$ microwave radiation. The recombination and trapping components

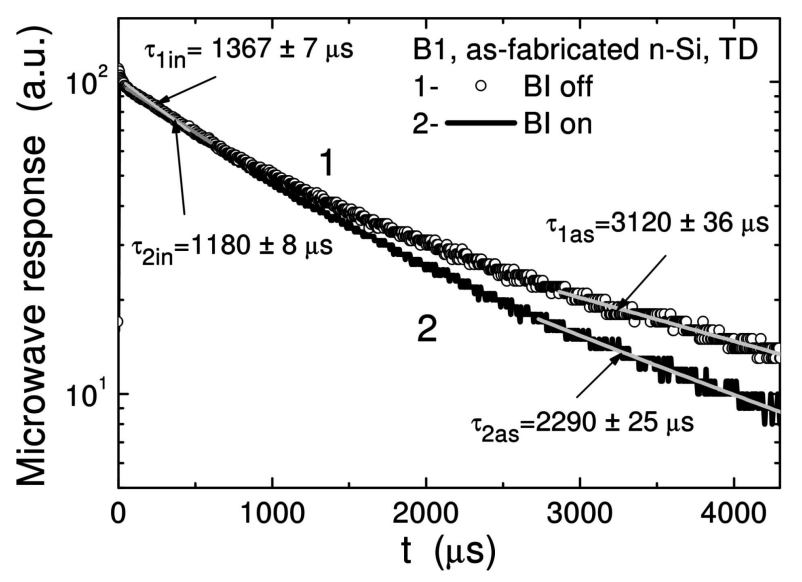

(a)

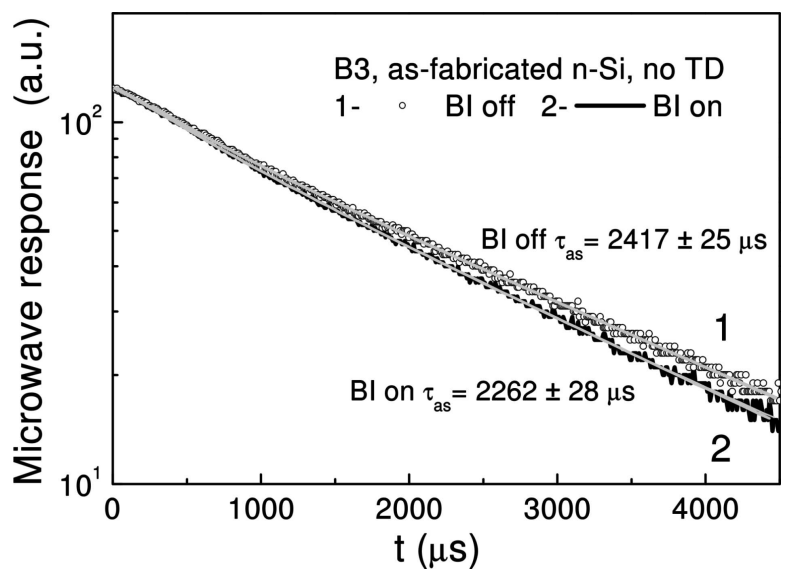

(b)

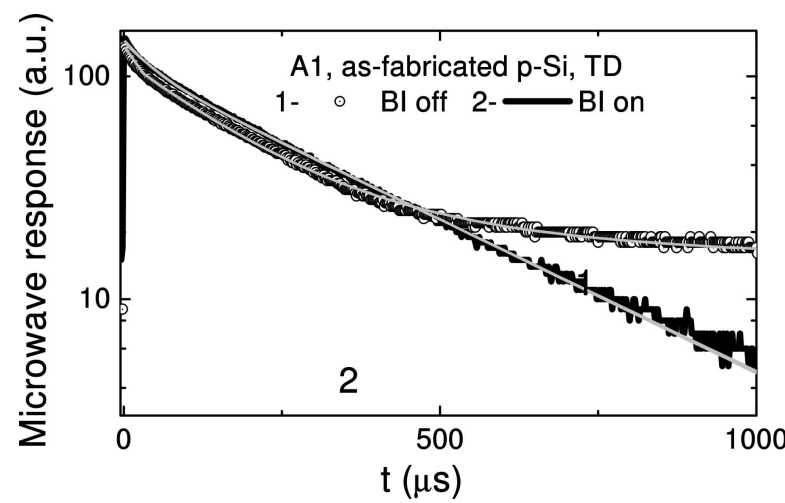

(c)

Fig. 1. MWA decays measured at $300 \mathrm{~K}$ in (a) MCZ $n$-type heated (TDs) and (b) untreated (no TDs) starting material wafers. (c) shows transients measured in $\mathrm{MCZ} p$-Si (presented for comparison). Grey lines correspond to the fits with parameters given in Table 2.

within excess carrier decay were examined at various carrier densities. Continuous white light bias illumination (BI) was employed to suppress trapping by emptying the trapping levels. To try to resolve recombination and trapping processes, changes of the instantaneous decay lifetime $\left(\tau_{\mathrm{i}}\right)$ with excess carrier density 
Table 1. Investigated samples.

\begin{tabular}{cccccccc}
\hline Type & \multicolumn{2}{c}{$\mathrm{MCZ} p-\mathrm{Si}$} & & \multicolumn{2}{c}{$\mathrm{MCZ} n-\mathrm{Si}$} & FZ $n$-Si \\
\cline { 2 - 3 } $\begin{array}{c}\text { Sample } \\
\text { processing }\end{array}$ & $\begin{array}{c}A 1, A 2 \\
\text { TDs }\end{array}$ & $\begin{array}{c}A 3, A 4 \\
\text { no TDs }\end{array}$ & & $\begin{array}{c}B 1, B 2 \\
\text { TDs }\end{array}$ & $\begin{array}{c}B 3, B 4 \\
\text { no TDs }\end{array}$ & \\
\hline $\begin{array}{c}\gamma \text {-ray irradiation } \\
\text { dose (MRad) }\end{array}$ & $50-370$ & 50 & & $50-370$ & 50 & 400 \\
\hline
\end{tabular}

were studied by varying the excitation light intensity. The samples were placed on a cold / hot finger to measure the lifetime temperature dependence $\left(\tau_{\mathrm{i}}-T\right)$. Activation energy values were determined from the slopes of the $\tau_{\mathrm{i}}$ versus $1 / T$ characteristic.

\section{Experimental observations}

Figure 1 illustrates MWA transients in the TD processed and unheated wafers of $n$-type $\mathrm{Si}$, measured at relatively low excitation with and without continuous bias illumination (BI). The initial (in) and asymptotic (as) lifetimes, $\tau_{\text {in }}$ and $\tau_{\text {as }}$, were determined either simply, from the tangents to the excess carrier decay curve at the initial part and the end of the transient, respectively, or, for more detailed analysis, by fitting to an exponential decay function to determine the experimental errors. The former data are relevant for a phenomenological analysis of the clearly non-exponential relaxation. The more detailed analysis, fitting the decay curve to the sum of a few exponentials, corresponds to the case of low level excitation [9] and can identify the constituents of the decay curve. The $\tau_{\text {in }}, \tau_{\text {as }}$, and constituents of the decay curves in Fig. 1(a,b) are given in Table 2.

These lifetimes vary differently with changing excitation intensity, bias illumination and temperature. Variations of $\tau_{\text {in }}$ are small, while $\tau_{\text {as }}$ changes considerably with excitation regime and temperature. The markedly non-exponential decay (Fig. 1(a,b), curve 1 in Fig. 1(c)) illustrates the competition of carrier recombination and trapping processes.

The conventional trapping process, understood to be caused by relatively shallow levels that capture and exchange the excess carriers with only one of the bands, is responsible for delaying the recombination of the carriers. The levels can be filled up by using additional bias illumination to suppress trapping and this leads to a decrease in the carrier lifetime. This can be seen by comparing the lifetimes obtained for different levels of bias illumination in Fig. 1(a,b). Occupancy of the trapping centres depends on the free carrier concentration. The recombination and trapping lifetimes decrease with excitation intensity, and the trapping component almost disappears at the highest excitation intensities. Such a non-exponential process can be described phenomenologically in terms of an instantaneous decay lifetime $\tau_{\mathrm{i}}=-n /(\partial n / \partial t)$, which is a function of the excess carrier density $n$.

In the simplified analysis of the experimental results the initial $\tau_{\text {in }}$ and the asymptotic $\tau_{\text {as }}$ are a measure of the lifetime of the recombination processes and of the trapping, respectively. In reality, this $\tau_{\text {in }}$ characterizes processes that can be influenced by other traps. This paper concentrates more on the asymptotic $\tau_{\text {as }}$, and the initial $\tau_{\text {in }}$ is analysed only to determine the influence of irradiation on the decay of photoconductivity. The evidence for a faster process is seen in the fit of Fig. 1 decay curves with a sum of three exponential functions. Peculiarities related to surface recombination in the non-irradiated silicon are discussed in [8]. The details of photoconductivity decay in the irradiated samples will be analysed elsewhere.

Within the current transient, $t \cong 0$ is ascribed to $\tau_{\text {in }}=\tau_{\mathrm{i}}(t \cong 0)$. Employing constant excitation intensity means that the initial excess carrier concentration is nearly the same at the beginning of decay in materials of the same resistivity. Thus, values of $\tau_{\text {in }}$ for different samples and temperatures can be compared when the overall carrier density relaxation process is nonexponential. The asymptotic time is defined in terms of the excess carrier density approaching the equilibrium carrier concentration (of the order of $10^{11} \mathrm{~cm}^{-3}$ in the investigated samples). The trapping constituents are therefore compared at the same excess carrier densities at the end of the decay (while these time instants are defined by the excess carrier density) by employing $\tau_{\text {as }}=\tau_{\mathrm{i}}\left(t \mid n_{\mathrm{ex}} \approx n_{\mathrm{eq}}\right)$ to characterize the significantly non-exponential process.

After irradiation, the instantaneous lifetimes of both components decrease relative to those of the as-fabricated material, and the lifetime is nearly independent of the level of excitation for low to moderate excitation levels. The inverse lifetime increases almost linearly with irradiation dose for both $n$ - and $p$-type material at room temperature, as shown in Fig. 2, but with different slopes for $\tau_{\text {in }}$ and $\tau_{\text {as }}$. This suggests a different introduction rate for recombination and trapping defects. 
Table 2. The constituents of the photoconductivity decay curves of Fig. 1 in heated (TDs) and untreated (no TDs) $n$-type MCZ starting material.

\begin{tabular}{cccccc}
\hline \multirow{2}{*}{$\begin{array}{c}\text { Decay } \\
\text { curve }\end{array}$} & \multirow{2}{*}{$\tau_{\text {in }}, \mu \mathrm{s}$} & \multirow{2}{*}{,$\mu \mathrm{s}$} & \multicolumn{2}{c}{$y=A_{1} \exp \left(-t / \tau_{1}\right)+A_{2} \exp \left(-t / \tau_{2}\right)+A_{3} \exp \left(-t / \tau_{3}\right)$} \\
\cline { 4 - 6 } & & & $\tau_{1}, \mu \mathrm{s}\left(A_{1}\right.$, a.u. $)$ & $\tau_{2}, \mu \mathrm{s}\left(A_{2}\right.$, a.u. $)$ & $\tau_{3}, \mathrm{~ms}\left(A_{3}\right.$, a.u. $)$ \\
\hline B1, BI off & $1400 \pm 27$ & $3120 \pm 36$ & $23 \pm 2(11 \pm 1)$ & $861 \pm 6(66 \pm 1)$ & $3.12 \pm 0.04(37 \pm 1)$ \\
$B 1$, BI on & $1227 \pm 24$ & $2290 \pm 25$ & $19 \pm 2(11 \pm 1)$ & $693 \pm 4(48 \pm 1)$ & $2.29 \pm 0.03(55 \pm 1)$ \\
$B 3$, BI off & $1890 \pm 32$ & $2417 \pm 25$ & & $526 \pm 16(21 \pm 1)$ & $2.42 \pm 0.03(110 \pm 1)$ \\
$B 3$, BI on & $1764 \pm 35$ & $2262 \pm 28$ & & $619 \pm 16(21 \pm 1)$ & $2.26 \pm 0.03(107 \pm 1)$ \\
$A 1$, BI off & $275 \pm 1$ & $49660 \pm 190$ & $10.5 \pm 0.7(21 \pm 1)$ & $180 \pm 1(97.5 \pm 0.3)$ & $49.7 \pm 0.2(20.1 \pm 0.2)$ \\
$A 1$, BI on & $221 \pm 3$ & $315 \pm 1$ & $54.7 \pm 1.6(33.4 \pm 0.5)$ & $319 \pm 1(109.1 \pm 0.5)$ & \\
\hline
\end{tabular}

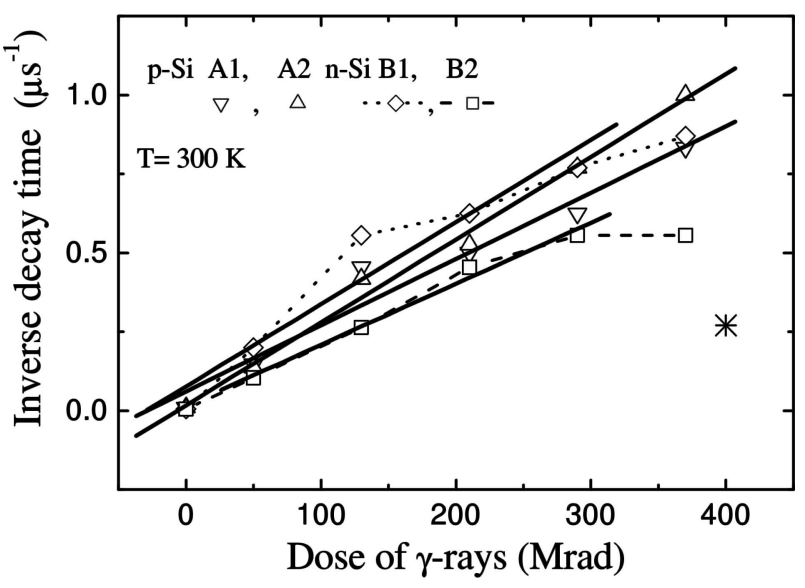

(a)

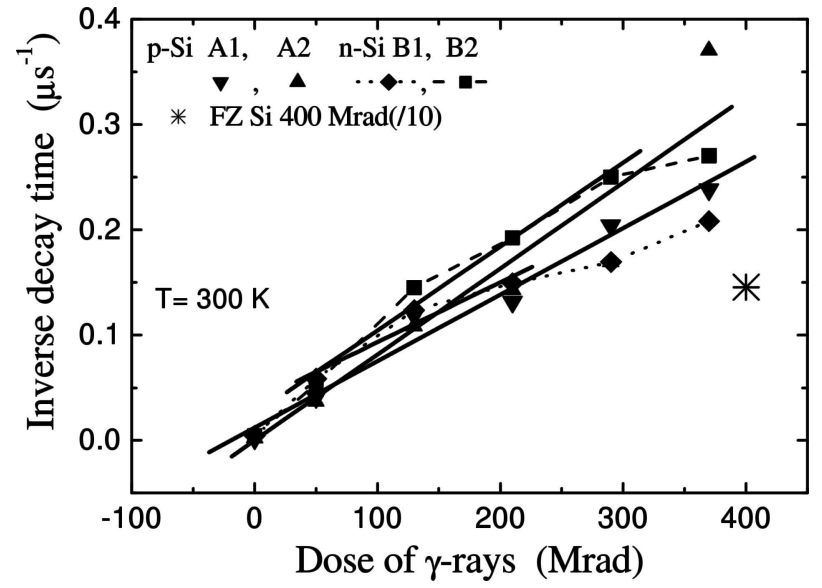

(b)

Fig. 2. Inverse instantaneous carrier lifetime versus $\gamma$-ray irradiation dose in different samples of $p$-type and $n$-type MCZ Si. (a) $\tau_{\text {in }}$, (b) $\tau_{\text {as }}$. The straight lines correspond to a linear fit for irradiated samples (the dotted lines are a guide to the eye for the $n$-Si experimental data).

However, a range of absolute lifetime values and deviations from linearity were found for the different samples. The fit to linear dependence is better in the $p$-Si. In $n$-Si at lower doses (up to $200 \mathrm{MRad}$ ) the fit to a linear dependence on dose is more obvious than at higher doses, where saturation is observed.

The $\tau_{\text {in }}$ and $\tau_{\text {as }}$ in MCZ Si are shorter than in the FZ Si. This is related with the influence of the higher oxygen content in MCZ Si.

The carrier lifetime in the material irradiated with a fixed dose appeared to depend on temperature in the range from 90 to $430 \mathrm{~K}$, as shown in Fig. 3. For both types of material and all irradiated samples a peak is observed in the asymptotic lifetime at lower than room temperatures, but the absolute lifetime values vary slightly in samples irradiated by different doses. Some of the peculiarities are shown in Fig. 3 for $n$ - and $p$-type material and for irradiated MCZ and FZ silicon samples. In the starting material, the lifetime versus temperature variations were not resolvable.

The low temperature peak is formed by the trapping long-tail component. This trapping component is nearly $\mathrm{BI}$ independent in the range of BI intensities applied. The characteristic values of the carrier lifetime and the effective thermal activation and quenching energies were deduced from a linear fit to the logarithm of lifetime versus $1 / k T$ plots and by fitting with the proposed models according Eqs. (4) and (5). They were found to be different in samples irradiated with various doses. The variations were weakly dependent on the nonequilibrium carrier density required to record a reliable MWA response and were similar in all samples.

The photoconductivity decay variation with temperature is rather complicated, as illustrated in a case of FZ Si (Fig. 3(d)). An intriguing, significant decrease of the lifetime at low temperature needs a more detailed analysis.

\section{Discussion}

The concentrations of recombination centres $R$ and trapping centres $M$, estimated at the lowest excitation in the as-grown material, are less than $10^{11} \mathrm{~cm}^{-3}$, and observed lifetimes are in the range of ms (Fig. 1). Bias illumination partially or fully suppresses the long-tail trapping component, which is more pronounced in the TD treated material (Fig. 1(a)). Trapping is also more 


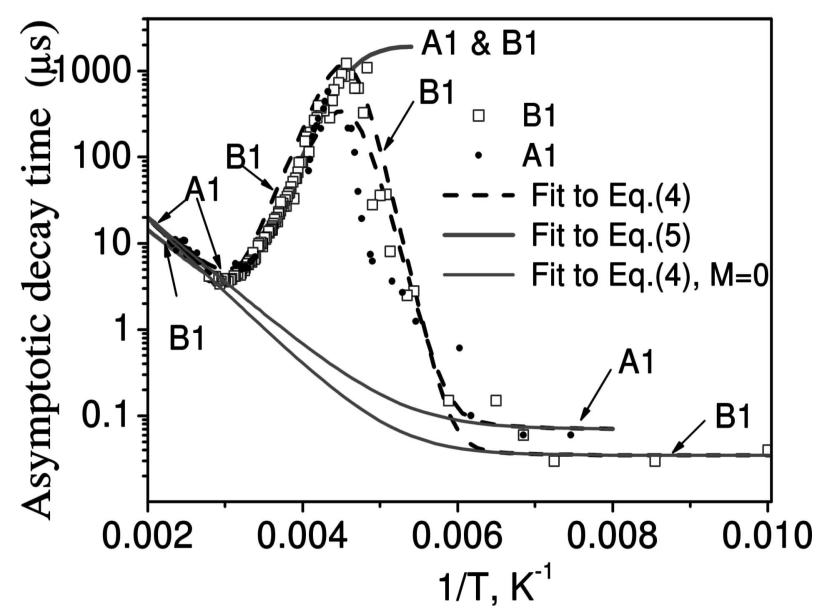

(a)

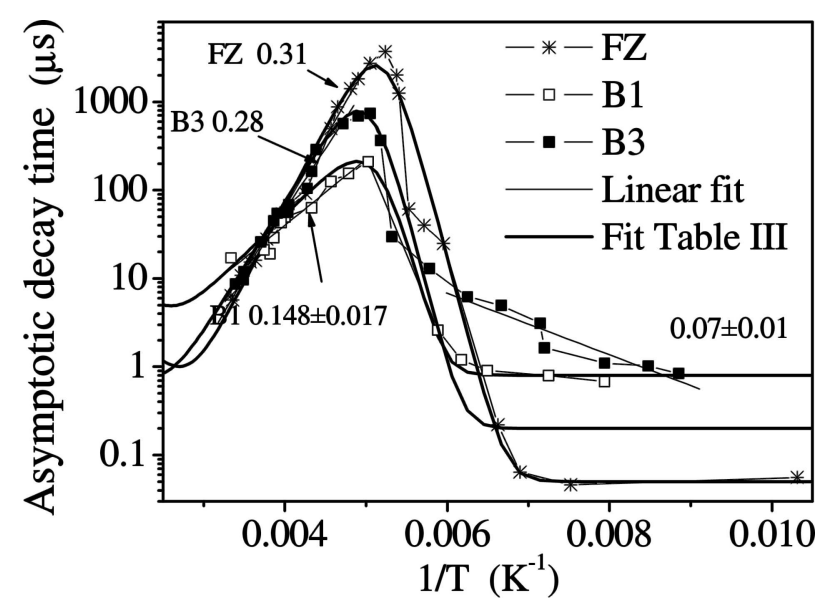

(c)

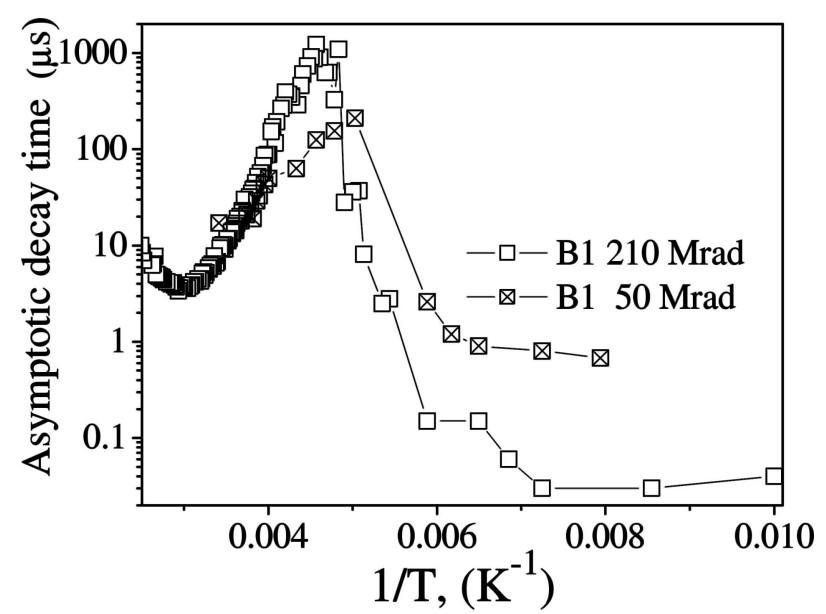

(b)

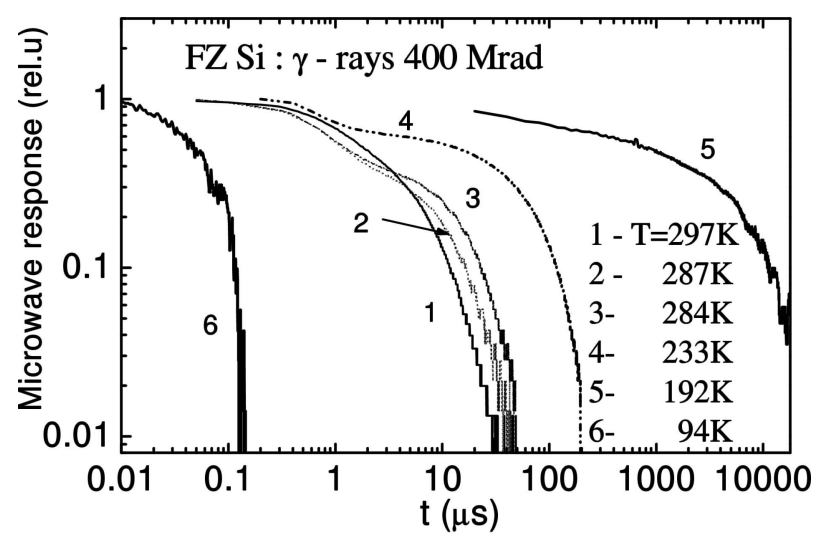

(d)

Fig. 3. (a) Carrier lifetime as a function of the inverse temperature in $210 \mathrm{MRad}$ irradiated wafers of $p$-type and $n$-type MCZ Si at the same excitation conditions; (b) compares the carrier lifetime in the sample $B 1$ after different levels of irradiation; (c) is the asymptotic decay lifetime in $50 \mathrm{MRad}$ irradiated wafers of $n$-type MCZ Si and in a $400 \mathrm{MRad}$ irradiated FZ pad detector at different temperature, and (d) is the normalized MWA decay at different temperature in the irradiated FZ Si. The lines in (a) and (b) are the simulation results with the parameters presented in Table 3. The dashed lines show the results if trapping is neglected. The insets in (c) are the effective activation (quenching) energies. The errors (if not shown) are $\sim 0.02 \mathrm{eV}$.

conspicuous in the $p$-type material (Fig. 1(c)). These observations are consistent with FTIR spectra, where the $\mathrm{O}_{\mathrm{i}}$-related absorption peak for the untreated $p$-Si material shows larger values than that of the TD processed $p$-type material and those of $n$-Si. More pronounced changes of peaks attributed to $\mathrm{O}_{\mathrm{i}}$ and $\mathrm{SiO}_{x}$ were also revealed in the FTIR spectra of irradiated wafers of both $n$ - and $p$-type, relative to those of the starting material. This implies consumption of $\mathrm{O}_{\mathrm{i}}$ in creation of complexes with radiation defects. The trapping centres might be ascribed to thermal donors grown-in within MCZ Si, with oxygen densities intentionally enhanced [10] relative to the FZ Si.

The interstitial oxygen concentration was estimated from FTIR spectra at $1106 \mathrm{~cm}^{-1}$, employing a baseline method [11-12] and using the IOC88 standard cal- ibration factor $F_{\mathrm{RT}}=3.14 \cdot 10^{17} \mathrm{~cm}^{-2}$ [13] at room temperature (RT). The measured value of less than $9 \cdot 10^{17} \mathrm{~cm}^{-3}$ is nearly the same in oxygenated $n$ - and $p$-Si starting material. Due to the overlapping of $\mathrm{O}_{\mathrm{i}}$ and $\mathrm{SiO}_{x}$ bands the absolute value of the $\mathrm{O}_{\mathrm{i}}$ concentration may be overestimated, while $\mathrm{O}_{\mathrm{i}}$ concentrations of about $5 \cdot 10^{17} \mathrm{~cm}^{-3}$ are inherent for MCZ Si [10]. However, these spectra do allow comparative evaluations. Thermal donor (TD) formation changes the $\mathrm{O}_{\mathrm{i}}$ concentration more in the $p$-Si. The oxygenation and heat treatments (TD procedure) probably introduce shallow levels which serve as trapping centres (TDs are characterized by energy factors of 0.07 and $0.15 \mathrm{eV}$ [12]). Assuming that the carrier lifetime at low excitation is mainly determined by capture of minority carriers, TDs are more efficient in $p$-type material, as observed in our 
experiments. Together with $\mathrm{O}_{\mathrm{i}}$, a peak at $1220 \mathrm{~cm}^{-1}$ is observable in the FTIR spectra that is attributed to $\mathrm{SiO}_{x}$ precipitates.

The non-exponential decay and variations with excitation regimes of the carrier density transients in the starting material imply that the relaxation process of excess carrier pairs is caused by at least two centres. The dependence of photoconductivity decay components on the background excitation shows the influence of local level filling. If one of the centres is characterized by similar values of the capture cross-section for electrons and holes, it acts as a recombination centre. If the other centre traps only one type of carrier and exchanges carriers with only one band, then the process of trapping-mediated recombination can be described in terms of the instantaneous lifetime $\tau_{\mathrm{i}}$ and trapping coefficient $K_{\text {tr }}$ [9]:

$$
\begin{gathered}
\tau_{\mathrm{i}}=\tau_{\mathrm{R}} K_{\mathrm{tr}}, \\
K_{\mathrm{tr}}=\left[1+\frac{M N_{\mathrm{VM}}}{\left(N_{\mathrm{VM}}+\Delta n\right)^{2}}\right] .
\end{gathered}
$$

Here, $\tau_{R}$ is the lifetime given by the Shockley-ReadHall (S-R-H) one-level recombination model, with the well-known dependence on excess carrier density $\Delta n$ and temperature $T$ [9]. The trapping coefficient (Eq. (2)) is determined by the concentration $M$ of trapping centres and the density of states $N_{\mathrm{VM}}=$ $N_{\mathrm{V}} \exp \left(-\Delta E_{\mathrm{M}} / k T\right)$. (If the trap is related to the conduction band, the index " $\mathrm{C}$ " is used and the $\Delta E_{\mathrm{M}}$ means the energy from the corresponding band.) The $N_{\mathrm{V}}$ is the effective density of band states. Hence the trapping coefficient increases during the relaxation process as the carrier density decreases, and the trapping effect appears as a long-tail component within MWA transients at relatively low excitation intensity. Trapping is suppressed with enhancement of $\Delta n$, via either excitation intensity or bias illumination, as observed in our experiments. Also, resolution of lifetime variations is determined by trap concentration, $M$. At low defect concentration and at temperatures for which the small number of carriers can be captured by traps, the trapping coefficient is small and the relaxation is controlled by recombination centres. The features of simultaneous recombination and trapping, simulated according to Eqs. (1) and (2), are illustrated in Fig. 4.

In the starting material, the lifetime-versus-temperature variations were not resolvable due to the low concentration of grown-in centres. The low temperature peak in the post-irradiated samples is most probably formed by the long-tail trapping decay component,

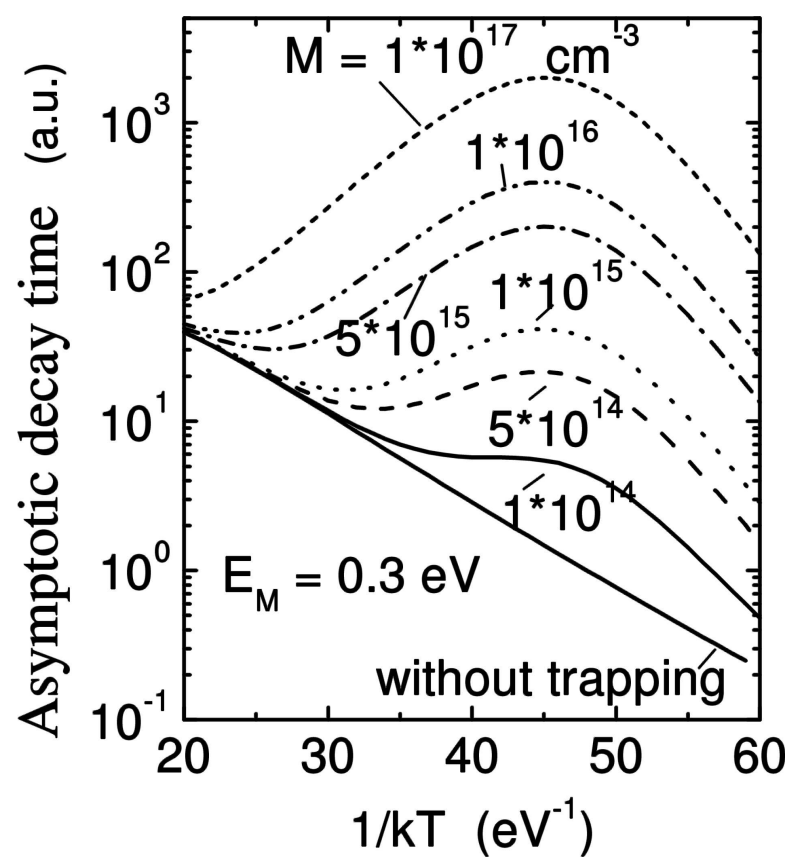

Fig. 4. Simulated instantaneous lifetime in the asymptotic decay as a function of the inverse thermal energy, calculated varying the concentration of the trapping centres at fixed excitation intensity.

which appears together with the initial, short component when the temperature is decreased. This model was used to analyse the temperature dependence of the asymptotic time constant presented in Fig. 3, adding into Eqs. (1) and (2) only an intrinsic carrier concentration, recombination centre activation energy, and recombination lifetime at low temperature. The full formula used is then:

$$
\begin{aligned}
\tau= & \tau_{\text {eff }}\left(1+\frac{M N_{\mathrm{CM}}}{\left(N_{\mathrm{CM}}+n_{\mathrm{i}}+n^{0}\right)^{2}}\right) \exp \left(\frac{-\Delta E_{\mathrm{R}}}{k T}\right) \\
& +\tau_{0} .
\end{aligned}
$$

Here $\tau_{0}$ and $\tau_{\text {eff }}$ are the lifetimes at low and high temperature $(\mathrm{T})$, correspondingly, $n_{\mathrm{i}}$ is the intrinsic free carrier concentration, $\Delta E_{\mathrm{R}}$ is thermal activation energy of the recombination $(\mathrm{R})$ centres. The best fit parameters for the experimental curves in Fig. 3 are given in Table 3. The relatively large number of fitting parameters did not allow of a simple procedure. The best fit parameters proved to be very sensitive to the decay asymptotic time constant activation and quenching energies and maximum temperature. The thermal activation of $\tau_{\text {eff }}$ was a parameter that allowed to achieve a fit of asymmetry of the peak in the temperature dependence of the asymptotic decay constant. The experiment and evaluation did not allow the trap type to be established, but for definiteness the parameters of the conduction or valence bands were used, as shown in the 
Table 3. A set of data for the best fit of experimental curves in Fig. 3 to the Eq. (3).

\begin{tabular}{cccccccc}
\hline Sample & $\tau_{\text {eff }}, \mu \mathrm{s}$ & $M, \mathrm{~cm}^{-3}$ & $\Delta E_{\mathrm{M}}, \mathrm{eV}$ & $n^{0}, \mathrm{~cm}^{-3}$ & $\Delta E_{\mathrm{R}}, \mathrm{eV}$ & $\tau_{0}, \mu \mathrm{s}$ & Trap for: \\
\hline B3, 50 MRad & 150 & $7.0 \cdot 10^{13}$ & 0.48 & $1.0 \cdot 10^{7}$ & 0.22 & 0.2 & $\mathrm{e}$ \\
B1, 50 MRad & 800 & $2.5 \cdot 10^{14}$ & 0.40 & $7.5 \cdot 10^{8}$ & 0.27 & 0.8 & $\mathrm{e}$ \\
B1, 210 MRad & 1000 & $8 \cdot 10^{10}$ & 0.56 & $2.0 \cdot 10^{6}$ & 0.17 & 0.035 & $\mathrm{e}$ \\
B1, 210 MRad & 1000 & $2.5 \cdot 10^{10}$ & 0.56 & $1.0 \cdot 10^{6}$ & 0.17 & 0.035 & $\mathrm{~h}$ \\
A1, 210 MRad & 650 & $5 \cdot 10^{10}$ & 0.48 & $8.0 \cdot 10^{7}$ & 0.15 & 0.07 & $\mathrm{~h}$ \\
FZ, 400 MRad & 180 & $4.2 \cdot 10^{12}$ & 0.495 & $1.5 \cdot 10^{6}$ & 0.18 & 0.04 & $\mathrm{e}$ \\
\hline
\end{tabular}

last column of the table. The differences made by this assumption are not great, as illustrated for the sample Bl (210 MRad), where both choices have been applied.

Also, the simulated effect of trapping in the model is illustrated by the dashed curves, where the trapping has been neglected. This difference is important in evaluating the role of trapping in $\tau_{\text {as }}$ and $\tau_{\text {in }}$ that will be used below.

The evaluated energies show the dominant effective trap level in the sample and their values correspond to observed deep levels in irradiated Si [14]. The deviations between simulation and experimental values can be understood in terms of the simultaneous activity of a few traps. Also, the temperature dependence of the non-equilibrium excess carrier concentration could explain the small difference in the widths of the simulated and experimental lifetime peaks. Further analysis needs more experimental results. The results for sample $B 3$ ( $n$-Si without TDs) shows evidence of an additional trapping activation process that also requires additional analysis. The weakness of this fit are the extracted activation energy values of the trapping centres because centres having this activation energy appear as the effective traps at higher temperatures than RT [14].

Among the intriguing results are a big decrease of the lifetime at low temperature and the large variations of $\tau_{\mathrm{as}}$ in rather small intervals of temperature. The known centres in silicon [14] cannot explain such features. Inter-centre recombination [15] could therefore play a central role in the highly irradiated material at low temperature, when tunneling plays an important role. In a more comprehensive analysis, defect clusters and configurational multi-stability of defects [16] should be taken into account at low temperatures. If the change of the recombination mechanism at low temperature is confirmed then a different trapping model should be considered. Instead of multiple trapping, as described by equations (1-3), a "slow" trap model could be used (incorporating single trapping before the recombination process [8]). In this model $\tau_{\text {as }}$ is defined by the thermal activation time constant:

$$
\tau_{\mathrm{as} / \mathrm{M}}=\frac{1}{\gamma_{\mathrm{M}}\left(N_{\mathrm{CM}(\text { or VM })}+n^{0}\right)} .
$$

According to this model the data presented in Fig. 3(a,c) would give the trap thermal activation energy values shown in the insets in Fig. 3, if the fit to experimental data were performed according to the modified Eq. (4) to include the recombination temperature dependence:

$$
\tau=\tau_{\text {eff }} \exp \left(-\frac{\Delta E_{\mathrm{R}}}{k T}\right)+\frac{1}{\gamma_{\mathrm{M}}\left(N_{\mathrm{CM}}+n^{0}\right)},
$$

corresponding to the case that the lifetime is defined by the longest time constant, the thermal activation rate or recombination [8]. The fitting parameters are given in Table 4. Here $\gamma_{M}$ is the carrier capture coefficient by the trap, given by $v \sigma_{M}$, where $v$ is the thermal velocity and $\sigma_{M}$ is the carrier capture cross-section.

The fit of this model is better than that given by Eq. (3), but both models need a more detailed analysis of the nature of recombination at low temperatures.

In the irradiated samples, the significantly decreased recombination lifetime values (at $T=300 \mathrm{~K}$ ) are evidently caused by radiation induced defects. The inverse recombination lifetime values as functions of irradiation dose were generalized by a linear fit, excluding the highest doses for $n$-Si. The straight lines in Fig. 2 represent these fitted data in MCZ Si for $\tau_{\text {in }}$ and $\tau_{\text {as. }}$. This approximation corroborates the increase of the concentration of radiation defects $N_{\gamma}, \propto \tau^{-1}$. The slope $\alpha=1$ of this dependence, $\tau^{-1} \propto N_{\gamma}^{\alpha}$, implies that the irradiation generates predominantly point defects. The data presented in Fig. 2 show that the rate of introduction of defects influencing $\tau_{\text {in }}$ and $\tau_{\text {as }}$ is not so different in the different samples.

The carrier lifetime dependence on irradiation dose (under the assumptions that the carrier capture lifetime is proportional to the irradiation dose and carrier 
Table 4. The fitting parameters in Eq. (5) for the results presented in Fig. 3(a, c).

\begin{tabular}{cccccc}
\hline Sample & $\Delta E_{\mathrm{M}}, \mathrm{eV}$ & $\gamma_{M}, \mathrm{~cm}^{3} \mathrm{~s}^{-1}$ & $n^{0}, \mathrm{~cm}^{-3}$ & $\Delta E_{\mathrm{R}}, \mathrm{eV}$ & $\tau_{\text {eff }}, \mu \mathrm{s}$ \\
\hline B3, 50 MRad & 0.28 & $4 \cdot 10^{-16}$ & $2.0 \cdot 10^{12}$ & & \\
B1, 50 MRad & 0.14 & $1 \cdot 10^{-18}$ & $1.5 \cdot 10^{15}$ & & \\
B1, 210 MRad & 0.38 & $3 \cdot 10^{-14}$ & $1.7 \cdot 10^{10}$ & 0.14 & 370 \\
A1, 210 MRad & 0.38 & $3 \cdot 10^{-14}$ & $1.7 \cdot 10^{10}$ & 0.14 & 370 \\
FZ, 400 MRad & 0.30 & $3.5 \cdot 10^{-15}$ & $1.3 \cdot 10^{11}$ & & \\
\hline
\end{tabular}

trapping can be neglected) is described according to the classical relation

$$
\frac{1}{\tau}=\frac{1}{\tau^{*}}+\sigma v N_{\gamma}=\frac{1}{\tau^{*}}+\sigma v\left(N_{\gamma 0}+\beta_{\gamma} D\right) .
$$

Here $\tau^{*}$ is the carrier capture time related to the centres which are not generated by irradiation, $N_{\gamma 0}$ is the initial defect concentration that depends on irradiation, $D$ is the irradiation dose, $\sigma$ is the capture cross-section, and $v$ is the thermal velocity. Value of the capture crosssection, inherent for the dominant defects, can be estimated from the slope of the $\tau^{-1}$ increase with irradiation dose $D$, in the case the parameter $\beta_{\gamma}$ is known. Earlier work [10] established the rate of defect introduction in Si containing different oxygen concentrations. According to these data, the defect introduction rate for our samples $\left(\mathrm{O}_{\mathrm{i}}\right.$ concentration $\left.\sim 5 \cdot 10^{17} \mathrm{~cm}^{-3}\right)$ is $\beta_{\gamma}=5.7 \cdot 10^{8} \mathrm{MRad}^{-1}$. The average slopes of $\tau^{-1}$ versus $D$ (Fig. 2(a,b)) are $0.0023 \pm 0.0003$ for $\tau_{\text {in }}$ and $(7 \pm 2) \cdot 10^{-4}$ for $\tau_{\text {as }}$. The difference in these values depends on the trapping. The measured difference of the $\tau_{\text {as }}$ and the fit to the experimental results, if trapping is neglected (the dashed curves of Fig. 3), shows a good correspondence of $\tau_{\text {in }}$ with the recombination lifetime. Value of the capture cross-section, ascribed to the centres that control $\tau_{\text {in }}$, is found to be $10^{-19} \mathrm{~cm}^{-2}$, as obtained from data in Fig. 2. This value is typical for a singly charged repulsive centre.

The nonlinear dependence which appears at higher doses for $n$-Si shows the possible effect of a defect reaction or an overlap of space charge regions, as well as a change in the competition between different centres. The data presented in Fig. 2 were measured at $300 \mathrm{~K}$. As follows from Fig. 3 (and the analysis given below), at this temperature the recombination centre and trap contributions are similar. The $\tau^{-1}$ versus $D$ in $n$-Si shows a nonlinear increase of the lifetime with irradiation, which can be explained by an increase of trap concentration. A more detailed analysis requires the investigation of $\tau^{-1}$ versus $D$ at different temperatures. This will be presented elsewhere.

The inverse recombination lifetime value measured in the FZ Si irradiated with a 400 MRad dose (indicated by an asterisk in Fig. 2) deviates significantly from this fitted average value for the largest irradiation doses in MCZ. The photoconductivity decay components at $T=300 \mathrm{~K}$ are shorter in MCZ Si than in FZ $\mathrm{Si}$ irradiated with doses of similar value. As the resistivity of the initial MCZ and FZ Si material was in the same range, differences in recombination lifetimes for the post-irradiated samples can be attributed to formation of oxygen related complexes.

\section{Conclusions}

The inverse lifetime of the recombination and trapping processes, estimated from MWA decays, showed a nearly linear increase with $\gamma$-ray irradiation dose in MCZ wafers, indicating a point defect formation process. The measured cross-section of these centres is consistent with the main role of singly charged repulsive centres.

The temperature dependence of the lifetime is explained by competition of trapping and recombination processes. The revealed difference in the dose and temperature dependences of the lifetime for standard FZ and $\mathrm{MCZ}$ can be explained by native defects in the starting material.

The parameters of recombination and trapping were determined by fitting experimental and simulated data with two alternative models and therefore the recombination model has to be analysed in more detail, especially at low temperatures.

\section{Acknowledgement}

This work was supported in part by the Lithuanian State Science and Studies Foundation and performed in the frame of the CERN RD39 and RD50 Projects.

\section{References}

[1] Z. Li, H.W. Kraner, E. Verbitskaya, V. Eremin, A. Ivanov, M. Rattaggi, P.G. Rancoita, F.A. Rubinelli, S.J. Fonash, C. Dale, and P. Marshall, Investigation of the oxygen-vacancy (A-centre) defect complex profile 
in neutron irradiated high resistivity silicon junction particle detectors, IEEE Trans. Nucl. Sci. 39, 17301738 (1992).

[2] G. Lindström, M. Ahmed, S. Albergo, et al., Radiation hard silicon detectors-developments by the RD48 (ROSE) collaboration, Nucl. Instrum. Methods A 466, 308-326 (2001).

[3] RD50 Status Report 2002/2003, CERN-LHCC-2003058.

[4] M. Moll, J. Adey, A. Al-Ajili, et al., Development of radiation tolerant semiconductor detectors for the Super-LHC, Nucl. Instrum. Methods A 546, 99-107 (2005).

[5] J. Härkönen, E. Tuovinen, P. Luukka, L. Kauppinen, Z. Li, M. Moll, A. Bates, and K. Kaska, Proton irradiation results of $p+/ n-/ n+\mathrm{Cz}-\mathrm{Si}$ detectors processed on $p$-type boron doped substrates with thermal donor induced space charge sign inversion, Nucl. Instrum. Methods A 552, 43-48 (2005).

[6] Z. Li, M. Bruzzi, V. Eremin, J. Härkönen, J. Kierstead, P. Luukka, D. Menichelli, E. Tuominen, E. Tuovinen, and E. Verbitskaya, Gamma radiation induced space charge sign inversion and re-inversion in $p$-type MCZ Si detectors and in proton-irradiated $n$-type MCZ Si detectors, Nucl. Instrum. Methods A 552, 34-42 (2005).

[7] T.O. Niinikoski, M. Abreu, P. Anbinderis, et al., Lowtemperature tracking detectors, Nucl. Instrum. Methods A 520, 87-92, 2004.

[8] E. Gaubas, Transient absorption techniques for investigation of recombination properties in semiconductor materials, Lithuanian J. Phys. 43, 145-165 (2003);
E. Gaubas, J. Vaitkus, E. Simoen, C. Claeys, and J. Vanhellemont, Excess carrier cross-sectional technique for determination of the surface recombination velocity, Mater. Sci. Semicond. Processing 4, 125-131 (2001).

[9] S.M. Ryvkin, Photoelectronic Effects in Semiconductors (Consulting Bureau, New York, 1964), ch. 6.

[10] Z. Li, J. Harkonen, W. Chen, J. Kirstaed, P. Luukka, E. Tuominen, et al., Radiation hardness of high resistivity magnetic Czochralski silicon detector after gamma, neutron and proton irradiations, IEEE Trans. Nucl. Sci. 51, 1901-1908 (2004).

[11] A. Sassella, A. Borghesi, and T. Abe, Quantitative evaluation of precipitated oxygen in silicon by infrared spectroscopy, J. Electrochem. Soc. 145, 1715-1719 (1998).

[12] E. Simoen, C. Claeys, R. Loo, O. De Gryse, P. Clauws, R. Job, A.G. Ulyashin, and W. Fahrner, Characterisation of oxygen and oxygen-related defects in highlyand lowly doped silicon, Mater. Sci. Eng. B 102, 207212 (2003).

[13] Annual book of ASTM standards, F 1188-93 (ASTM, Philadelphia, 1993).

[14] V. Eremin, E. Verbitskaya, and Z. Li, Effect of radiation induced deep level traps on $\mathrm{Si}$ detector performance, Nucl. Instrum. Methods A 476, 537-549, 2002.

[15] W.M. Chen, B. Monemar, and E. Janzen, Direct observation of intercentre charge transfer in dominant nonradiative recombination channels in silicon, Phys. Rev. Lett. 61, 1914-1917 (1991).

[16] A. Chantre, Introduction to defect bistability, Appl. Phys. A 48, 3-9 (1989).

\title{
KRŪVININKU REKOMBINACIJOS DOZINIAI KITIMAI $\gamma$ SPINDULIUOTE APŠVITINTAME Si, IŠTIRTI NENUOSTOVIOSIOS MIKROBANGU SUGERTIES BŪDU
}

\author{
J. Vaitkus ${ }^{\text {a }}$, Z. Li ${ }^{\text {b }}$, J. Härkönen ${ }^{\mathrm{c}}$, E. Gaubas ${ }^{\text {a }}$

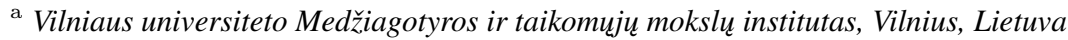 \\ ${ }^{\mathrm{b}}$ Brukheiveno nacionaline laboratorija, Aptonas, Niujoroko valstija, JAV \\ ${ }^{\mathrm{b}}$ Helsinkio universitetas, Helsinkis, Suomija ir CERN, Ženeva, Šveicarija
}

\section{Santrauka}

Ištirti rekombinacijos parametrų doziniai ir temperatūriniai kitimai Si, apšvitintame $\gamma$ spinduliuote, siekiant atskleisti vyraujančiu radiacinių defektų susidarymo ypatumus. Aptikta, kad nepusiausvirųju krūvininkų tankio relaksacijos būdingos trukmès mažèja kvazitiesiškai su $\gamma$ spinduliuotės apšvitos doze. Krūvininkų tankio relaksacijos sandai sietini su rekombinacijos bei prilipimo vyksmais ir lemia ryškius trukmių kitimus, kaitaliojant bandinio temperatūrą tarp 100 ir $350 \mathrm{~K}$. Temperatūrinès aktyvacijos spektre aptiktos efektinès trukmès kitimu smailès, iš kurių ìvertinti krūvininkų gaudykliu parametrai. Aptariami vyraujantys radiaciniai defektai sietini su aptiktais rekombinacijos būdingųjų dydžių kitimais. 